\title{
Dentists welcome new drive to cut childhood obesity
}

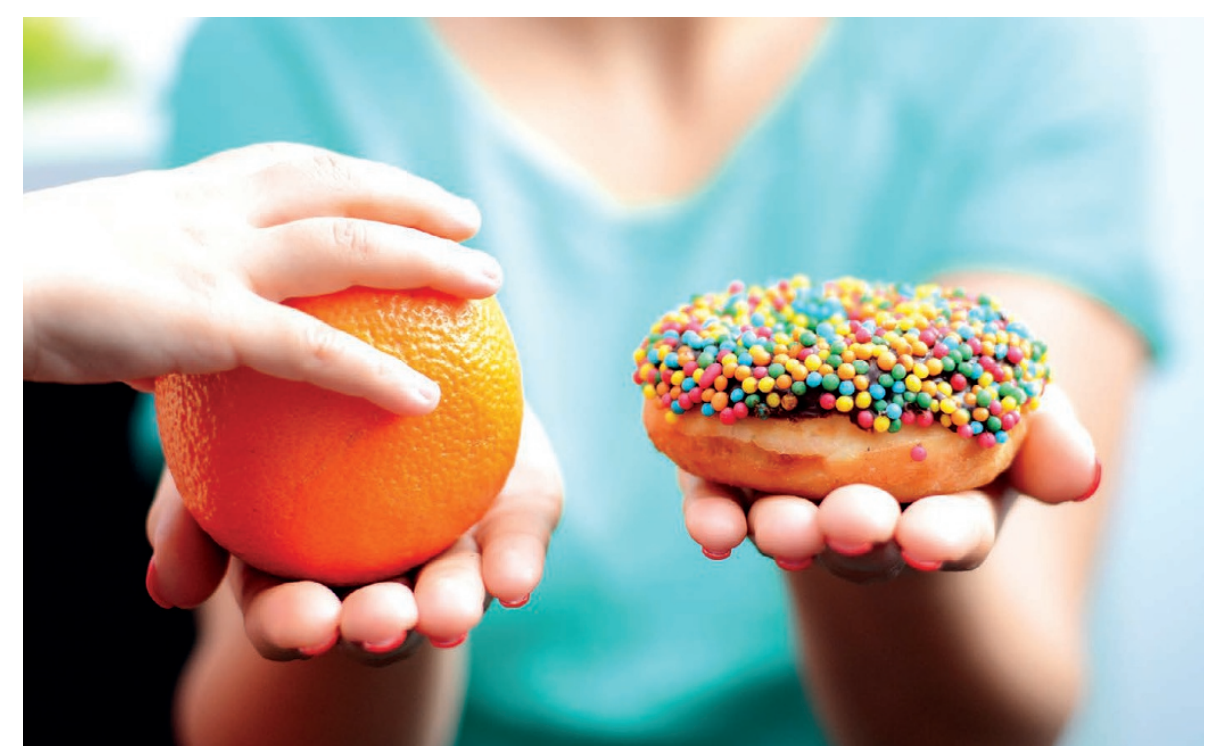

Dentists' representatives have generally welcomed the recent publication of chapter two of the Childhood Obesity Strategy, ${ }^{1}$ describing it as a more substantial effort to tackle the issue.

However, there was still a need for more focus on action on oral health, said the BDA.

The government's next chapter of its childhood obesity strategy published on 25 June 2018 promises more action on junk food marketing with new advertising restrictions being introduced to stop foods high in sugar being targeted at children, including a potential $9 \mathrm{pm}$ watershed on adverts for the unhealthiest products.

The BDA said that despite the welcome pledges, it regretted that closely related issues on tooth decay had struggled for prominence.

Renewing the call for a dedicated, fully funded strategy to address children's oral health, BDA Chair Mick Armstrong said: 'After a watered-down obesity strategy, we're pleased ministers have offered a more substantial second course. Progress is tribute to unrelenting pressure from both campaigners and health professionals.

'Action on the marketing and sale of high sugar products are necessary steps to address the major health challenges this country now faces. Sadly given we know about the agents fuelling these conditions, and common challenges we face tackling deep health inequalities, it's a missed opportunity that government hasn't quite joined the dots on obesity and tooth decay.

'There is a lot of talk about putting the mouth back in the body. When tooth decay is the number one reason for child hospital admissions, it needs to be more than a PS in someone else's strategy'.

Professor Michael Escudier, Dean of the Faculty of Dental Surgery, also welcomed the new measures in the strategy, saying: 'Excessive sugar consumption is a major cause of both obesity and tooth decay, so these new policies will make a significant contribution to addressing the poor state of children's oral health in this country, where nearly a quarter of five-year-olds have decayed teeth.

'The Faculty, along with many organisations across the health sector, has been calling for action on advertising and price promotions for some time. We are therefore delighted that the government has recognised the need to put our children's health first and act on this.

'However, it is important that we don't lose focus in our battle against tooth decay. Recent statistics have shown that decay is on the rise in parts of the country where it is already high, including the North West, the West Midlands and Yorkshire and The Humber, so there is still more work to be done to ensure no child has to endure preventable dental pain.'

1. Department of Health and Social Care. Childhood obesity: a plan for action, chapter 2. Available at https://www.gov.uk/ government/publications/childhood-obesity-a-plan-for-action-chapter-2 (accessed 4 July 2018). 